\title{
Investment in cocoon-silk and structure of the clusters of cocoons produced by gregarious microgastrine wasps (Hymenoptera: Braconidae)
}

\author{
Jun TAGAWA ${ }^{1}$ and YoshiBumi SATO² \\ ${ }^{1}$ Department of Biosphere-Geosphere System Science, Faculty of Informatics, Okayama University of Science, Okayama 700-0005, \\ Japan; e-mail: tagawa@big.ous.ac.jp \\ ${ }^{2}$ Kyoto College of Medical Science, Sonobe, Nantan, Kyoto 622-0041, Japan; e-mail: sato@kyoto-msc.jp
}

Key words. Braconidae, Microgastrinae, Glyptapanteles liparidis, Cotesia glomerata, Cotesia kariyai, cocoon, cocoon cluster, body size, silk investment, aggregation

\begin{abstract}
After leaving their hosts, the larvae of endoparasitic braconid wasps pupate in cocoons. To determine their investment in cocoon silk, the dry weight of newly emerged wasps and that of the empty cocoons were measured for three gregarious braconid species of slightly different sizes: Glyptapanteles liparidis (Bouché), Cotesia glomerata (L.) and Cotesia kariyai (Watanabe) (Hymenoptera: Braconidae, Microgastrinae). These braconids form clusters of cocoons of different types. Glyptapanteles liparidis is significantly larger than either of the Cotesia species, and C. kariyai is the smallest. The ratio of the weight of cocoon silk to the total weight of cocoon silk, wasp body, cast cuticle and meconium is smaller for small species than large species. Small species economise on their use of silk by aggregating cocoons and can therefore invest a larger fraction of their resources in adult body mass. Moreover, the larvae of the smallest species, C. kariyai, additionally reduce their use of silk by constructing a communal airy silk layer beneath which the individual cocoons are formed.
\end{abstract}

\section{INTRODUCTION}

Some insects pupate in cocoons, which protect the pupae from weather and natural enemies. Cocoon properties reflect the ecology and habitats of these cocoonspinning insects (Danks, 2004). Robust cocoons of the tasar silkworm Antheraea mylitta (Drury) (Lepidoptera: Saturniidae) protect the pupae from desiccation during long periods of low humidity and high temperatures (Tripathi \& Singh, 1983). The cocoon of the soybean pod borer Leguminivora glycinivorella (Matsumura) (Lepidoptera: Tortricidae) protects overwintering pupae from drowning when the soil becomes waterlogged (Sakagami et al., 1985). The cocoon of the cat flea Ctenocephalides felis (Bouché) (Siphonaptera: Pulicidae) repels predacious ants (Silverman \& Appel, 1984).

The cocoons must be both physically durable and physiologically resilient to ensure the survival of the pupae inside them. A tough cocoon requires a large investment in terms of silk. If two similarly shaped insects of different body size, e.g., one is half the length of the other, invest the same fraction of their total mass in cocoon silk, the cocoon wall thickness of the smaller individual would be half that of the larger insect. The energy loss of the small pupa is double that of the large pupa because the small pupa's surface area per unit of body weight is twice that of the large pupa. Therefore, the expectation is that small individuals will invest proportionally more in cocoon silk than large individuals. In this respect, the relation between body size and proportional investment in cocoon silk is worthy of study.

Braconid wasps are generally small parasitoids that spin cocoons either on the hosts' food plants or in the soil after larval egression. If the cocoons are exposed to the elements, the survival of the pupae is likely to depend on the toughness of the cocoons, as is the case for other cocoonspinning insects. Survival of the gregarious parasitoid Cotesia kariyai (Watanabe) in incompletely spun cocoons is low in dry conditions (Kawaguchi \& Tanaka, 1999). The cocoon of the parasitoid Cotesia glomerata (L.) protects the immobile pupa from natural enemies such as ants and desiccation (Tagawa, 1996; Tagawa \& Satoh, 2008). The wet weight of a cocoon can be as much as half the weight of the emerging wasp, which is a remarkably high investment in cocoon silk (Tagawa, 1996). For some ichneumonid wasps, the cocoons spun by the summer generations are thinner than those spun by overwintering wasps (Clausen, 1940; Askew, 1971), suggesting that these wasps are able to adjust the investment in cocoon silk according to the environmental conditions. It is thought that there is a trade-off between the amount of silk used for constructing a cocoon and the mass of the adult that emerges from the cocoon. Therefore, the cost of constructing a cocoon is critically important for cocoonspinning insects, particularly small species.

This study was designed to reveal the relation between the amount of cocoon silk and body mass in small cocoon-spinning insects. We determined the investment in cocoon silk of three species of gregarious braconids (Microgastrinae): Glyptapanteles liparidis (Bouché), Cotesia glomerata and Cotesia kariyai. Adults of these species are a few millimetres in length and similar in body shape, but their cocoons differ.

Glyptapanteles liparidis parasitises the gypsy moth caterpillar, Lymantria dispar (L.) (Lymantriidae). The host caterpillars feed on the leaves of many tree species, such 

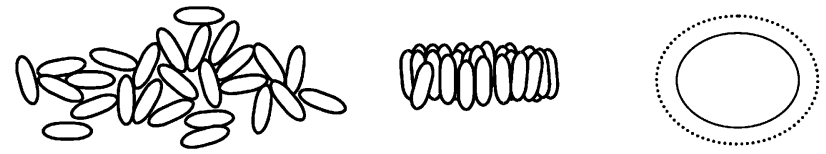

Fig. 1. Schematic drawings of the clusters of cocoons (top view) of three gregarious braconid wasps, Glyptapanteles liparidis, Cotesia glomerata and Cotesia kariyai. Dozens of $C$. kariyai cocoons are packed in a single mass covered with an airy silk layer. Therefore, individual cocoons are not visible.

as maple, cherry and persimmon, where cocoons of $G$. liparidis can be found loosely grouped on the surface of leaves. Cotesia glomerata is a principal parasitoid of the cabbage worm, Pieris rapae crucivora Boisduval (Pieridae). Typically, piles of cocoons of this species are found on leaves of cabbage. Cotesia kariyai specifically parasitises the caterpillar of Pseudaletia separata (Walker) (Noctuidae), which feeds on the leaves of Gramineae. The cocoons of $C$. kariyai are packed in a ball-like mass covered with an airy silk layer. The cocoon clusters of these parasitoids are often seen on leaves in open spaces.

\section{MATERIAL AND METHODS}

Cocoon clusters of three braconid parasitoids (Microgastrinae), G. liparidis, C. glomerata and C. kariyai (Fig. 1), and their respective host caterpillars, $L$. dispar, $P$. rapae crucivora and $P$. separata, were collected from fields during spring in Okayama and Kyoto, Japan. The cocoon clusters were placed individually in $30-\mathrm{ml}$ glass vials and kept at $20^{\circ} \mathrm{C}$ and a $16 \mathrm{~L}$ : $8 \mathrm{D}$ photoperiod. The hosts, which were already parasitised, were reared in 350-ml plastic cups, fed with leaves of their food plants and kept at room temperature until the parasitoid larvae egressed. Within a day of egressing from their hosts they formed clusters of cocoons, which were kept at $20^{\circ} \mathrm{C}$ and a $16 \mathrm{~L}$ : $8 \mathrm{D}$ photoperiod.

Immediately after the adults emerged from the cocoons, the wasps and empty cocoons were dried at $80^{\circ} \mathrm{C}$ for more than 24 h. Subsequently, the wasps and the empty cocoons were weighed separately to the nearest $0.01 \mathrm{mg}$ using an electronic balance (1712MP8; Sartorius AG, Germany). After removing larval cuticles and meconia from the empty cocoons, the net weight of the silk cocoons was determined. The C. kariyai cocoon cluster was covered with an airy silk layer, which was removed and weighed. The weight of the cuticles and meconia was calculated by subtracting the net weight of cocoon silk from that of empty cocoons. Accordingly, the weights of adult wasps, cocoon silk and the larval cuticles plus meconia were obtained for each cocoon cluster. After weighing, the cocoons in each cluster were counted. Then three dry-weight values per cocoon were calculated for each cluster. The sum of these three weights was treated as the whole weight of a single cocoon. For $C$. kariyai, the dry-weight of the outer silk-layer per cocoon was calculated in addition to that of the weight of the silk in each cocoon. Each calculated weight was an average of the weight for both sexes because every cluster yielded both sexes, with a female bias.

\section{Data analysis}

The correlation between the size of the cluster of cocoons and weight of the wasp, weight of silk and the cocoon silk-weight ratio (weight of cocoon silk / weight of whole cocoon [= cocoon silk + adult wasp + shed larval cuticle + meconium]) was determined for each species. The weights of the three species, respective weights of each fraction of a whole cocoon and the cocoon silk-weight ratios, were compared using the Kruskal-Wallis test. Then multiple comparisons were performed using Dunn's procedure (Zar, 1999).

\section{RESULTS}

The weights of the wasps (mean $\pm \mathrm{SD}$ ) of G. liparidis, $C$. glomerata and $C$. kariyai were, respectively, $0.471 \pm$ $0.117 \mathrm{mg}(n=27), 0.314 \pm 0.058 \mathrm{mg}(n=23)$ and 0.264 $\pm 0.037 \mathrm{mg}(n=10)$ (Table 1$)$. The weights of the wasps of these three species differed significantly (KruskalWallis test, $H=32.1, p<0.0001)$. Glyptapanteles liparidis was significantly larger than either of the other two species (Dunn's procedure, $p<0.001$ ). In addition, C. kariyai was the smallest of the three, but the difference between the two Cotesia species was not significant.

The weight of $G$. liparidis was not influenced by the number of wasps (= cocoons) in a cluster $(r=0.127, \mathrm{~ns})$. However, the weights of the wasps of $C$. glomerata and $C$. kariyai were negatively and significantly dependent on the number of wasps in a cluster $(p<0.001)$. Correlation coefficients were, respectively, -0.648 and -0.939 . The silk weights per cocoon were similarly lower for larger clusters ( $C$. glomerata, $r=-0.550, p<0.01 ; C$. kariyai, $r$ $=-0.819, p<0.01)$. Accordingly, for all the species examined, the silk-weight ratios (cocoon silk weight / whole cocoon weight) were independent of the number of cocoons in a cluster $(G$. liparidis, $r=0.016 ; C$. glomerata, $r=0.164 ; C$. kariyai, $r=-0.111$; all ns). The average silk-weight ratios of $G$. liparidis, C. glomerata

TABLE 1. The dry weights (mean $\pm \mathrm{SD}, \mathrm{mg}$ ) of the components of single-cocoons and silk weight ratios of three gregarious braconid species, Glyptapanteles liparidis, Cotesia glomerata and Cotesia kariyai. Samples were dried at $80^{\circ} \mathrm{C}$ for more than $24 \mathrm{~h}$.

\begin{tabular}{|c|c|c|c|c|c|c|c|}
\hline \multirow{2}{*}{$\begin{array}{l}\text { Parasitoid } \\
\text { species }\end{array}$} & \multirow{2}{*}{$\begin{array}{l}\text { No. cocoon } \\
\text { clusters } \\
\text { examined }\end{array}$} & \multirow{2}{*}{$\begin{array}{l}\text { No. cocoons } \\
\text { per cluster } \\
(\text { mean } \pm \mathrm{SD})\end{array}$} & \multicolumn{4}{|c|}{ Dry weight (mean $\pm \mathrm{SD}, \mathrm{mg}$ ) of } & \multirow{2}{*}{$\begin{array}{l}\text { Silk weight } \\
\text { ratio }^{2}\end{array}$} \\
\hline & & & Cocoon silk & Wasp body & $\begin{array}{l}\text { Cuticle and } \\
\text { meconium }\end{array}$ & Whole cocoon ${ }^{1}$ & \\
\hline G. liparidis & 27 & $14.2 \pm 23.6$ & $0.490 \pm 0.117^{\mathrm{a}}$ & $0.471 \pm 0.117^{\mathrm{a}}$ & $0.088 \pm 0.024^{a}$ & $1.049 \pm 0.230^{\mathrm{a}}$ & $0.47^{\mathrm{a}}$ \\
\hline C. glomerata & 23 & $27.5 \pm 6.7$ & $0.226 \pm 0.038^{b}$ & $0.314 \pm 0.058^{b}$ & $0.059 \pm 0.017^{b}$ & $0.599 \pm 0.089^{b}$ & $0.38^{\mathrm{b}}$ \\
\hline C. kariyai & 10 & $57.2 \pm 17.6$ & $\begin{array}{c}0.155 \pm 0.026^{b} \\
\{0.084 \pm 0.016\}^{3}\end{array}$ & $0.264 \pm 0.037^{b}$ & $0.021 \pm 0.014^{\mathrm{c}}$ & $0.439 \pm 0.070^{\mathrm{b}}$ & $0.35^{\mathrm{b}}$ \\
\hline
\end{tabular}

Within columns, values followed by different letters are significantly different $\left(p<0.01\right.$, Dunn's procedure). ${ }^{1}$ Cocoon silk + wasp + larval cuticle \& meconium; ${ }^{2}$ weight of cocoon silk / weight of whole cocoon; ${ }^{3}$ weight of the outer layer of cocoon-cluster per cocoon. 
and $C$. kariyai were $0.47,0.38$ and 0.35 , respectively (Table 1).

Inter-specifically, the silk-weight ratio of the larger species was higher than that of either of the smaller species and significantly different among the three species (Kruskal-Wallis test, $H=39.8, p<0.0001$ ). The silkweight ratio of $G$. liparidis was significantly higher than that of either $C$. glomerata or $C$. kariyai (Dunn's procedure, $p<0.001)$. The difference between the two Cotesia species was not significant. The smallest species, $C$. kariyai, used more than half its investment in silk $(0.084$ $\mathrm{mg} / 0.155 \mathrm{mg}$ ) in covering the cluster of cocoons with the airy silk layer.

An individual of the smaller species invested a larger proportion of its resources in body mass than did individuals of the larger species. Nevertheless, the net body weight of the largest species ( $G$. liparidis) was 1.8 times $(0.471 \mathrm{mg} / 0.264 \mathrm{mg})$ that of the smallest species $(C$. kariyai).

\section{DISCUSSION}

Because of a mutual trade-off, the adult mass of cocoon-spinning insects is influenced by the amount of silk used in constructing the pupal case (Stevens et al., 1999). Therefore, the balance between economy and robustness of cocoons is important for cocoon-spinning insects. To date, only the cocoon weights of a few insects, such as silkworms and bees, have been investigated (Wightman \& Rogers, 1978; Tripathi \& Singh, 1983; Parker, 1984; Tepedino \& Parker, 1986; Dash et al., 1992; Bosch \& Vicens, 2002), and no silk investment data are reported for parasitic wasps.

In the three braconid species studied, the cocoon-silkweight ratio of the larger species was higher than those of the smaller species. In other words, small species invest a larger fraction of their resources in adult body tissues than large species. From the results it is not apparent whether or not there is a sexual difference in resource allocation in these species. However, this does not affect the conclusion, as the sex ratios of the adults that emerged from the clusters were similar.

The cocoon clusters of these three wasps differed structurally (Fig. 1). The cocoons of the largest species, $G$. liparidis, are loosely grouped into a cluster. Cotesia glomerata generally forms a dense cluster composed of a pile cocoons. The cluster of the smallest wasp, C. kariyai, resembles a soft cotton-ball, within which the cocoons are embedded.

Each cocoon of $G$. liparidis is similar to that of a solitary wasp. Even if there is contact between some of the cocoons, each must be protected against the elements and natural enemies. Cotesia glomerata cocoons occur in piles and as a consequence less of the surface area of each cocoon is exposed than in solitary cocoons, which must be advantageous for $C$. glomerata because physiological stresses are likely to be directly related to the surface area of a cocoon. The mode of construction of each cocoon saves some silk. The economical use of silk should be beneficial because valuable resources are invested in cocoon silk (Quicke et al., 2004). The cocoon-spinning behaviour of $C$. glomerata might have evolved to conserve silk. In addition, the compactness of the clusters of cocoons is expected to reduce the overall incidence of cocoon parasitism (Tagawa \& Fukushima, 1993; Tanaka \& Ohsaki, 2006).

The cocoon cluster of $C$. kariyai differs greatly from those of $G$. liparidis and $C$. glomerata. The mass of $C$. kariyai cocoons can be regarded as a large single cocoon, as the airy outer layer covers the large mass of cocoons. Of the silk produced by this species, more than half is used in the construction of the cover and less than half in that of the individual cocoons. As a consequence the individual cocoons are likely to be very soft and vulnerable. Even if all the silk were used in the construction of the individual cocoons, the resultant capsules would still be weaker than those of the other two wasps, as this species uses less silk (Table 1). In this type of cocoon cluster, only a small amount of silk is used in the construction of the cocoon cover that functions as the protective barrier. Furthermore, by conserving silk in this way gregarious wasps are able to invest a larger fraction of their total resources in body mass.

The larvae need to aggregate within a small area in order to produce a compact mass of cocoons. Furthermore, to construct a common silk layer, it is necessary for the larvae to continue producing silk threads as they aggregate. Although this behaviour seems to be cooperative, it is possible that such aggregates could be assemblages of selfish individuals (Hamilton, 1971). Sato et al. (1983) report that $C$. kariyai larvae manipulate the behaviour of the host caterpillar P. separata when they egress from the host: "During parasitoids' egression, the host larva never moves, ... after the completion of egression the host army worm suddenly moves forwards and leaves the cloudy silk mass ... Then the parasitoid larvae commence spinning their own cocoons and finally make up a large cocoon cluster like a cotton ball." If they did not manipulate host behaviour, a ball-like cluster could not be formed. Evidently, the behaviour of C. kariyai larvae is adaptive in terms of the mutual trade-off between adult mass and the amount of silk used in the construction of the cocoon.

The present results indicate that small gregarious wasps economise on the use of silk in cocoon construction and that the structure of cocoon clusters is related to the size of the wasps. To test this hypothesis additional investigations on other related parasitoids are needed. The amount of silk in the cocoons of solitary wasps is worthy of further investigation if gregarious wasps achieve a larger body size by aggregating. These cocoon-spinning wasps are not considered to be small. Some parasitoids are smaller than the braconid wasps examined in this study. However, the very small wasps do not form cocoons. Cocoons are likely to be too costly, particularly for small insects. In fact, the vast majority of small parasitoids pupate within what remains of the bodies of their hosts, e.g., egg chorions, which like cocoons function as protec- 
tive barriers. Consequently, they can invest more of their resources in adult mass.

ACKNOWLEDGEMENTS. We wish to express our gratitude to M. Natori, M. Kuroda and T. Hikida for their advice on statistics. Thanks are also extended to J.A. Harvey for his valuable comments on the manuscript.

\section{REFERENCES}

AsKew R.R. 1971: Parasitic Insects. Heinemann Educational Books, London, 316 pp.

Bosch J. \& Vicens N. 2002: Body size as an estimator of production costs in a solitary bee. Ecol. Entomol. 27: 129-137.

Clausen C.P. 1940: Entomophagous Insects. McGraw-Hill, New York and London, $688 \mathrm{pp}$.

Danks H.V. 2004: The roles of insect cocoons in cold conditions. Eur. J. Entomol. 101: 433-437.

Dash A.K., NaYAK B.K. \& Dash M.C. 1992: The effect of different foodplants on cocoon crop performance in the Indian tasar silkworm Antheraea mylitta Drury (Lepidoptera: Saturniidae). J. Res. Lepid. 31: 127-131.

Hamilton W.D. 1971: Geometry for the selfish herd. J. Theor. Biol. 31: 295-311.

Kawaguchi M. \& TanaKa T. 1999: Time and location of larval emergence of the endoparasitoid Cotesia kariyai (Hymenoptera: Braconidae) from the lepidopteran host Pseudaletia separata (Lepidoptera: Noctuidae). Ann. Entomol. Soc. Am. 92: 101-107.

PARKER F.D. 1984: The nesting biology of Osmia (Trichinosmia) latisulcata Michener. J. Kans. Entomol. Soc. 57: 430-436.

Quicke D.L.J., Shaw M.R., Takahashi M. \& Yanechin B. 2004: Cocoon silk chemistry of non-cyclostome Braconidae, with remarks on phylogenetic relationships within the Microgastrinae (Hymenoptera: Braconidae). J. Nat. Hist. 38: $2167-2181$.

Sakagami S.F., Tanno K., Tsutsui H. \& Honma K. 1985: The role of cocoons in overwintering of the soybean pod borer Leguminivora glycinivorella (Lepidoptera: Tortricidae). $J$. Kans. Entomol. Soc. 58: 240-247.
Sato Y., Tanaka T., Imafuku M. \& Hidaka T. 1983: How does diurnal Apanteles kariyai parasitize and egress from a nocturnal host larva? Kontyû 51: 128-139.

Silverman J. \& Appel A.G. 1984: The pupal cocoon of the cat flea, Ctenocephalides felis (Bouché) (Siphonaptera: Pulicidae): a barrier to ant predation. Proc. Entomol. Soc. Wash. 86: 660-663.

Stevens D.J., Hansell M.H., Freel J.A. \& Monaghan P. 1999: Developmental trade offs in caddis flies: increased investment in larval defence alters adult resource allocation. Proc. R. Soc. Lond. (B) 266: 1049-1054.

TAgawa J. 1996: Function of the cocoon of the parasitoid wasp, Cotesia glomerata L. (Hymenoptera: Braconidae): Protection against desiccation. Appl. Entomol. Zool. 31: 99-103.

Tagawa J. \& Funushima H. 1993: Effects of host age and cocoon position on attack rate by the hyperparasitoid, Eurytoma sp. (Hym.: Eurytomidae), on cocoons of the parasitoid, Cotesia (= Apanteles) glomerata (Hym.: Braconidae). Entomophaga 38: 69-77.

TAgawa J. \& SAтOH Y. 2008: Effects of relative humidity on cocoon formation and survival in the braconid wasp Cotesia glomerata. Physiol. Entomol. 33: 257-263.

TANAKA S. \& OHSAKI N. 2006: Behavioral manipulation of host caterpillars by the primary parasitoid wasp Cotesia glomerata (L.) to construct defensive webs against hyperparasitism. Ecol. Res. 21: 570-577.

TEPEDINO V.J. \& PARKER F.D. 1986: The relationship between cocoon weight and prepupal weight in Megachile rotundata (Hymenoptera: Megachilidae). Pan-Pac. Entomol. 62: 289-292.

Tripathi A.K. \& Singh S.S. 1983: Some observations on the cocoons and pupa of Antheraea mylitta (Saturniidae: Lepidoptera) during summer season. Indian J. Zootomy 24: 17-21.

Wightman J.A. \& Rogers V.M. 1978: Growth, energy and nitrogen budgets and efficiencies of the growing larvae of Megachile pacifica (Panzer) (Hymenoptera: Megachilidae). Oecologia 36: 245-257.

Zar J.H. 1999: Biostatistical Analysis. 4th ed. Prentice Hall, Upper Saddle River, NJ, 929 pp.

Received December 17, 2008; revised and accepted April 20, 2009 